\title{
UNDERWATER PHOTOGRAMMETRY METHODS FOR A PECULIAR CASE-STUDY: SAN DOMENICO (PRATO-ITALY).
}

\author{
E. Pruno ${ }^{a}$, C. Marcotulli ${ }^{\text {a }}$, G. Vannini ${ }^{\text {a }}$, P. Drap ${ }^{\text {b }}$ \\ a (University of Florence, Italy) elisapruno53@gmail.com \\ b Aix Marseille Université, CNRS, ENSAM, Université De Toulon, LSIS UMR 7296,13397, Marseille, FRANCE
}

\author{
Commission WG V/2
}

KEY WORDS: Medieval Archaeology, survey, photogrammetry, pottery, database.

\begin{abstract}
:
San Domenico Church (Prato, Tuscan, Italy) is a very peculiar case of terrestrial archaeology surveyed with underwater archaeological photogrammetric approach. The vault of the choir was completely filled by a very important numbers of potteries, which is very interesting building technique. To document this technique a complete photogrammetric survey was realized, layer by layer, following underwater archaeology system. It is interesting to note that in underwater archaeology such a case is quite rare, in fact or the wreck is in shallow water and the digging can be made (but this case is now unrealistic because in shallow water all the wreck have been stolen - or already excavated by archaeologist - !) or we are in deep water, with well conserved wreck but the depth doesn't allow the excavation. In the last case only a surface survey is possible. Also for these reasons this particular case- study is very interesting in order to test underwater methods on real case. This experimentation is a good opportunity to develop and check methods, algorithm and software to obtain a relevant model of the site merging 3D measure and knowledge about the artefact as typology, theoretical model, spatial relationship between them. Even if this work started in 2006, with now obsolete digital camera and with a photographic campaign which not respect always the current constraints for building a dense cloud of point in photogrammetry,it is now used as a case-study for developing a relevant approach for underwater archaeology survey.
\end{abstract}

\section{INTRODUCTION}

San Domenico Church in Prato (Tuscany, Italy) is a very peculiar case of terrestrial archaeology surveyed with underwater photogrammetric approach.

In fact the vault of the choir was completely filled by hundreds of intact pottery vessels disposed, on four overlapping layers, for functional purposes (vessels are a resistant but light building material). It is a very interesting and unusual way of building, known since the Late Antiquity to Modern era. To document this situation a complete photogrammetric survey was realized, layer by layer, following underwater archaeological method. The main criteria, and similarities, were:

\section{need to proceed quickly with the excavation;}

- extreme difficulty to represent precisely, with the traditional method of direct relief, the dozens of ceramic forms for each level;

- need to represent, at best, the volumetric measure of the vessels overlapping on each other.

It is interesting to note that in underwater archaeology such a case is quite rare, in fact or the wreck is in shallow water and the digging can be made (but this case is not realistic because in shallow water all the wreck have been stolen - or already excavated by archaeologist - !) or we are in deep water, with well conserved wreck but the depth doesn't allow the excavation. In the last case only a surface survey is possible. Also for these reasons this particular case- study is very interesting in order to test underwater methods on real case.

\section{ARCHAEOLOGICAL NEEDS}

Two different digging campaigns were conducted by the Chair of Medieval Archaeology from the University of Florence; the first was in the 1990 and the second one in 2006 (Vannini 2001, Vannini \& Marcotulli, 2006).

The excavation in San Domenico is important from many points of view:

- first of all it has allowed the archaeologists to acquire one of the most important ceramic contests of medieval Tuscany. Thanks to the comparisons between archaeological analysis and written documentation, in fact, we can date quite exactly the findings back to the first three decades of the 14th century AD (Pruno \& Marcotulli 2014);

- on a second hand, an important goal of the research was understand and scientifically document the special building technique, which involved the use of ceramics as construction material. Recent studies, in fact, attest a broad widening of this particular way of building, since the Late Antiquity, but very few are the known examples dating to Middle Ages; 
- another important interest point is that most of the pottery used as filling is intact. This is very important because it is possible to study in the best way different typologies (especially the coarse ware) very often well know only by excavation sherds. Furthermore this pottery is a very interesting indicator of the urban pottery production in a relevant city of the Medieval Tuscany.

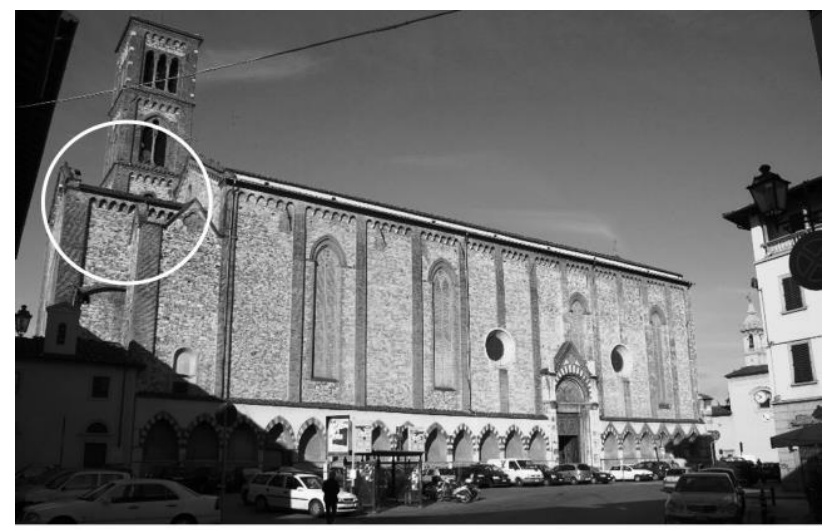

Figure 1. San Domenico church (Prato, Italy): localization of the vaulted room

About the main topic of this poster, we'll put the attention on the specific technique of surveying, chosen to adequately record this special archaeological deposit. The choice derives from the site's logistic, as we told in the introduction, and from a scientific question.

About the particular building technique with ceramics as building material, often the scholars note that is cheap but suitable, because the pottery is lighter than stone blocks and easier to procure (directly from the urban kilns, from the dumps or, simply, by recycling no longer used pottery). But how really worked the medieval masons? It was important to be an expert? This is the most important question and to answer we need to penetrate the medieval building technique very accurately.

In fact the archaeologists, to understand the way the medieval masons worked and to record this special technique, have removed a vessel at a time, starting from the top layer, more recent, and arriving to the bottom, more ancient, using the stratigraphic method (Harris 1989). So it was very important to precisely survey every group of pots (identified as a Stratigraphic Unit: US). Only in this way it was possible to understand all the building sequences and well define the characters of this technique. For the first time it has been possible to recognize all the Stratigraphic Units (interfaces, nucleus, mortars), allowing archeologist to stress the microphases of building in their three dimensions. It is important to note that the first layer of deposition is yet in situ to show the particularity of this technique.

\section{3D SURVEY}

During the second digging campaign both laser scanner and photographic survey were used. Even if the survey was done in 2006, without sophisticated digital camera and with a "rough" laser scanner, it is now possible to process all these data in order to produce an interesting model.

This experimentation is a good opportunity to develop and check methods, algorithm and software to obtain a relevant model of the site merging 3D measure and knowledge about the pottery as typology, theoretical model, and spatial relationship between them. Three steps are presented in this case-study, still in progress:

Orientation of all the layers (i.e. in this case stratigraphic unit) in the same reference system.

Merging photogrammetric data with laser scanner one, as it should be done in underwater archaeology merging acoustic and optic data, in order to obtain a model supporting artefact and surrounding.

Introduction of theoretical object model, adapted to the specific instance, in the final model instead of the surface obtained by photogrammetry. This is done inferring the right theoretical model on specific geometric primitive identified in relevant place both on the model and on the artefact.

Even if this work started in 2006, with now obsolete digital camera and with a photographic campaign which not respect always the current constraints for building a dense cloud of point in photogrammetry, it is now used as a case-study for developing a relevant approach for underwater archaeology survey.

\section{UNDERWATER SURVEY METHODOLOGY}

This work, for the pottery vessels survey methodology was strongly inspired from the Etruscan wreck Grand Ribaud F, surveyed in 2000 by DRASMM, COMEX and CNRS. (Drap, Bruno, Long, Durand, \& Grussenmeyer, 2002; Drap, Seinturier, \& Long, 2003) (Drap \& Long, 2006).

Another experimentation with pottery vessels survey was done during the VENUS project in Pianosa Island in Tuscany (Alcala et al., 2008). Both of them are adequately commensurate to San Domenico characteristics. Some other methods to produce 3D models of amphorae using partial measure from underwater photogrammetry have been experimented, for example using large target on the rims (Skarlatos, Demestiha, \& Kiparissi, 2012). In this case study we strickly apply the method described in (Drap \& Long, 2005b).

The photogrammetric survey in Pianosa was generated with a set of overlapping photographs. As the Pianosa site was $35 \mathrm{~m}$ deep, we were able to use both divers and ROV. The Venus team determined area to be surveyed around the wreck and it was prepared with $4 \times 2 \mathrm{~m}$ scale bars and a set of 15 cement block makers in order to define a network for better ROV guidance and to define a stable reference system for future survey.

Even if the two approaches are very close (both the survey in Prato and in Pianosa) the presence of water involves three main difference: in underwater context we do not have easily a stable reference system in order to survey all the layers during the excavation. We use additional cement block which can be considered as stable during the excavation. The second point is the scale: in underwater context we haven't the possibility to measure accurately distances between clear targets, even if we have made a survey by SONAR. It should be less accurate and not relevant for giving an accurate scaled reference system (it should be possible but really expensive) to obtain the exact scale. To do this the easier way is to introduce scale-bar directly on the site. Another way should be to use a calibrated, synchronized stereo system but also this is more expensive. In San Domenico site we are able to obtain many measured distances for each layer.

Finally the last one, but not the least one, is the way to mark and recognize material present on the site when archaeologist plans 
to take them off. Indeed archaeological excavation is a destructive operation and one of the main problems is to recognize all artefacts when they are on site. How to identify an amphora visible on a photograph, then on a survey then on board and finally in the warehouse with a lot of similar object? During the excavation done in 2000 on the Etruscan wreck the Grand Ribaud $F$, two solutions were tested. The first one, visible on Figure 2, was to put, by ROV, a numbered buoy in each amphora. This was done by ROV, before the photogrammetric survey and before the divers' intervention. The idea was to ask divers to take both amphora and buoys and put them together in an appropriate big basket used to bring artefact to surface.

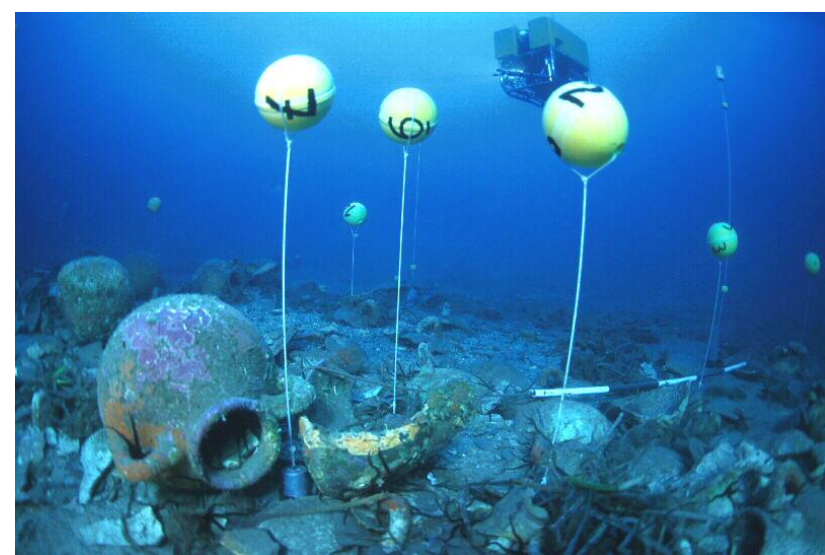

Figure 2. The amphorae lying on the sea bed, after the discovery of the wreck, August 2000.

During the second operation made in 2001 on Grand Ribaud F, we ask divers to put a ID label on each amphora before the survey. These two solutions are not perfect, some label can be lost, and both of they are time consuming. A perfect solution is still needed. In San Domenico site, more easily, we put label on pottery vessels to recognize them.

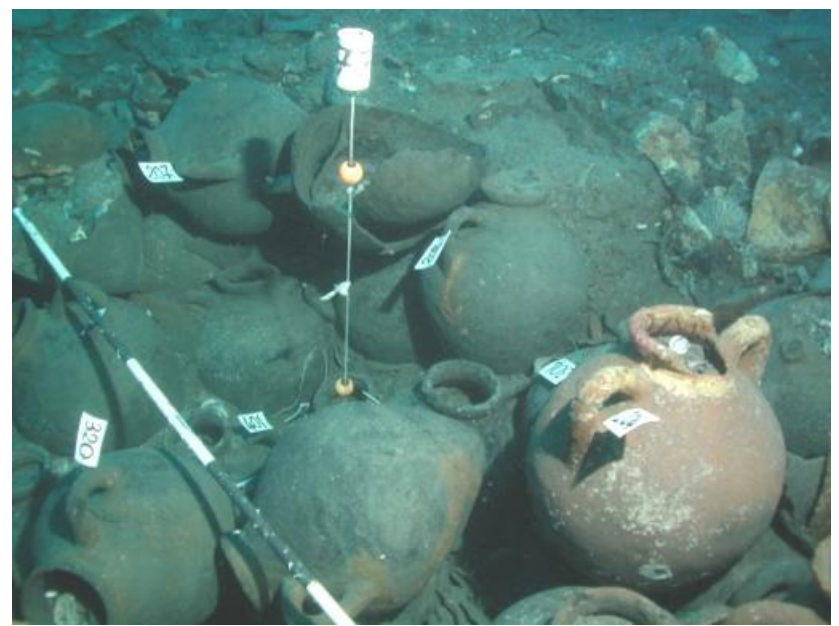

Figure 3. Amphorae lying on the sea bed, with a buoys for a reference to vertical and a rule for scaling (Drap \& Long, 2005a).

We can see on Figure 3 the ID label linked on each amphora, a scale bar and a buoy with two balls in order to give an observation on the verticality. The buoy is here used as a plumb line.

\subsection{Modelling amphorae}

At Pianosa site, archaeologists identified six types of amphora and each of them was converted into geometric templates. Modellers used sample of amphora carefully collected by divers that represented all recognized typologies. After the 3D models had been created, the amphorae were returned to the seabed. The diversity of the objects handled by the archaeologists and the geometric complexity of their surfaces led us to search for stable morphological characteristics where diagnostic measurements could be taken from the photographs. A series of simple dimensions were used to approximate these morphological characteristics. In the case of the amphorae we defined four measurable zones: rims, handle, belly and base and a set of geometric primitives computed by the least squares method onto the measured points. For example, a circle on the rim or belly points, a line on the base point and the centre of these two circles.

Archaeologist then would use specially written software to analyse the photogrammetry and generate the 3D amphorae database. This process would typically consist of:

1. Recognize the amphora type from the photographs and selecting the correct amphora type from a pull down menu;

2. Specify the measurements of the amphora with data points on the photographs where possible;

3. Add archaeological comments and observations;

4. Use the measured points to construct a new instance of a 3D virtual amphora;

5. Store this new instance in the remote database.

Finally, it's time to merge all the data together. We integrated the Pianosa terrain data from the sonar bathymetry mission, the photogrammetric data for texture mapping and the amphorae model database. This data, stored in a relational database can be used along with a set of java tools to wrap objects from the database into a VRML representation or OpenSceneGraph data file. This final output file contains a link for every amphora to the database via a $\mathrm{PhP}$ interface. This interface allows the user to view, check and modify the archaeological values regarding the amphorae. Of course the user still has access to all the raw data such as measuring points, photos and photo orientation used to measure the artefact.

The precision for all the photographs is around $2 \mathrm{~cm}$ and the relative error is less than $5 \mathrm{~mm}$ when the signal is good. The absolute accuracy is around $40 \mathrm{~cm}$ (using the control points given by the acoustic measurement from the ROV).

We decided to use these experiences to realize the site survey in San Domenico and to create a database of all the pottery vessels.

\subsection{Applying to terrestrial case study}

During the San Domenico excavation a similar approach was applied. A survey of the structure was done with laser Scanner, this is very similar to the bathymetric survey often done in underwater environment. Both of these technics are expensive and they need sophisticated device. Every time it is possible archaeologists try to not use this tool and focus more on archaeological excavation. Photogrammetry, when the site 
surface to cover is not too large can be an efficient alternative to these techniques.

After the general survey made on the structure in Prato, with a laser scanner, a photographic campaign was done before every excavation on each layer. First all the pottery vessels were labelled and they were used to feed a relational database.

The structure, visible in every photographic campaign, was used to define a common reference system. Of course in this terrestrial case this is much more simple and do not require particular operation before the survey. Indeed this was not thought at the beginning (in 2004) but during the photogrammetric process we had enough data to compute this common reference system.

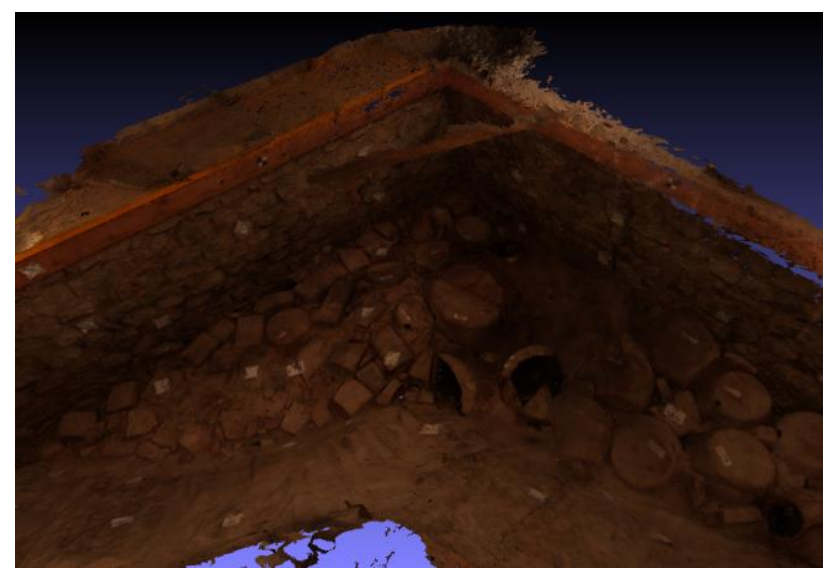

Figure 4. Photogrammetric survey of layer (US) 3, Prato. All the pottery is labelled in order to identify both the instance in the database and its typology.

In the same way the reference to vertical and the scale were automatically provided by the laser scanner survey. The photogrammetric survey was done using the original photographic campaign, even it was originally more dedicated to archaeological documentation than to photogrammetric needs. The survey obtained by Laser Scan campaign and photogrammetric campaign was used both to research goal (identification of the building characteristics and to define a pottery typological database) and to reconstructive goal. In fact now we are in train to open a museum on the site of San Domenico and we use 3D survey to reconstruct the archaeological context.

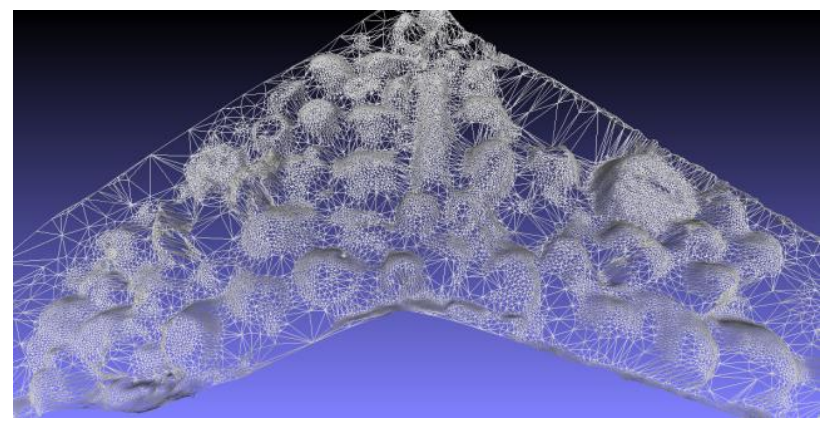

Figure 5. Mesh of a single layer used for extraction of pottery instances.

Layer by layer we extract pottery instances, like in Figure 4 example. The mesh built with layer photographic is very interesting for communication goals (Figure 6). In fact we are able to show the image of the excavated layer (US) (that now it doesn't exist anymore!).
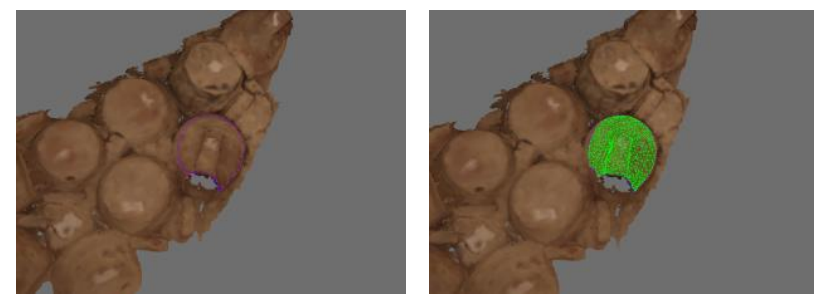

Figure 6. Manual extraction of a single instance in a mesh built on layer three.

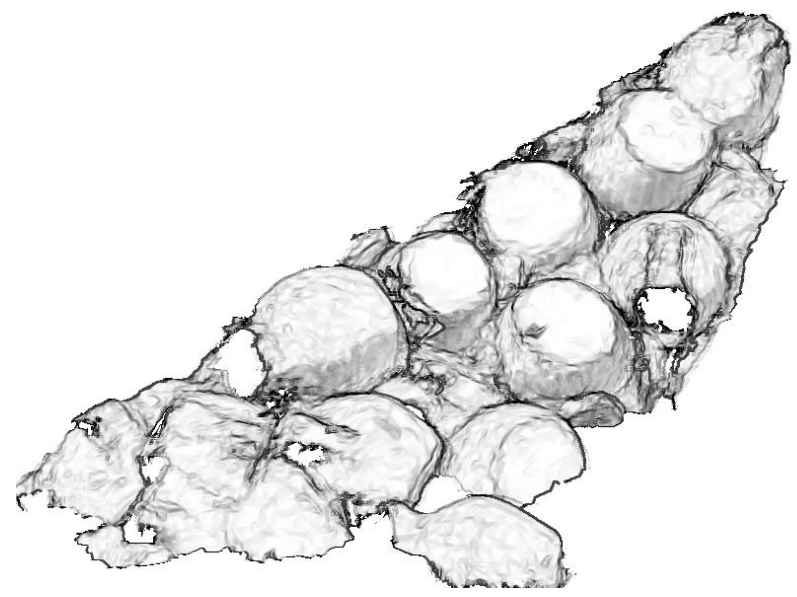

Figure 7. NPR representation of layer three in order to extract relevant line defining pottery individuals.

Defining pottery individuals (Figure 7, 9, 10) in each layer (US) has been very relevant to adequately document the building technique used in San Domenico church (Pruno \& Marcotulli 2014). But also identify exactly the theoretical model of all the vessels is very interesting because usually, concerning medieval period, the archaeologists are involved with many little sherds instead of entire vessels. So it is very import to have a model to compare exactly the small pieces found during excavation.

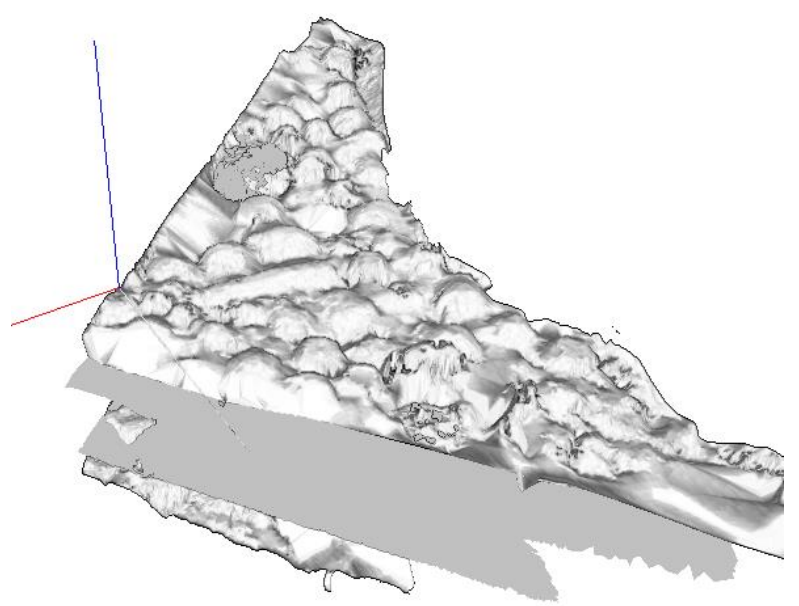

Figure 8. NPR representation of several layers in the same reference system. 

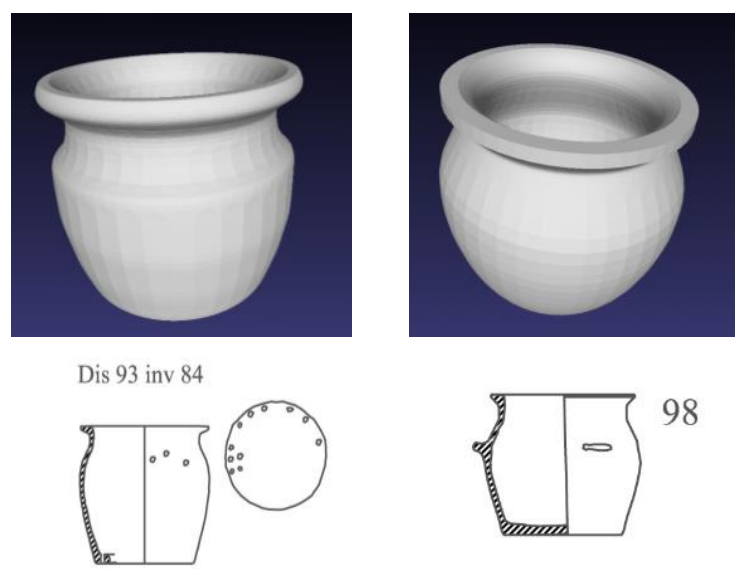

Figure 9.Theoretical model generation.

It is very important to stress the way to obtain the theoretical model generation and representation of each pottery vessel found during the excavation. On site we realized a photographic survey of each layer (US), which means, in this specific casestudy, of a very big amount of entire pottery vessels. Then we proceeded with the excavation activity, removing all the vessels. The third step was realizing the traditional, manual survey of each vessel and then it has been possible to use the measurement useful to generate the theoretical model. The peculiar character of the medieval pottery is to be an artisanal product, so each vessel, thought of the same typology, is slightly different of another. For this reason it is very important realize a theoretical model starting to real measurement.
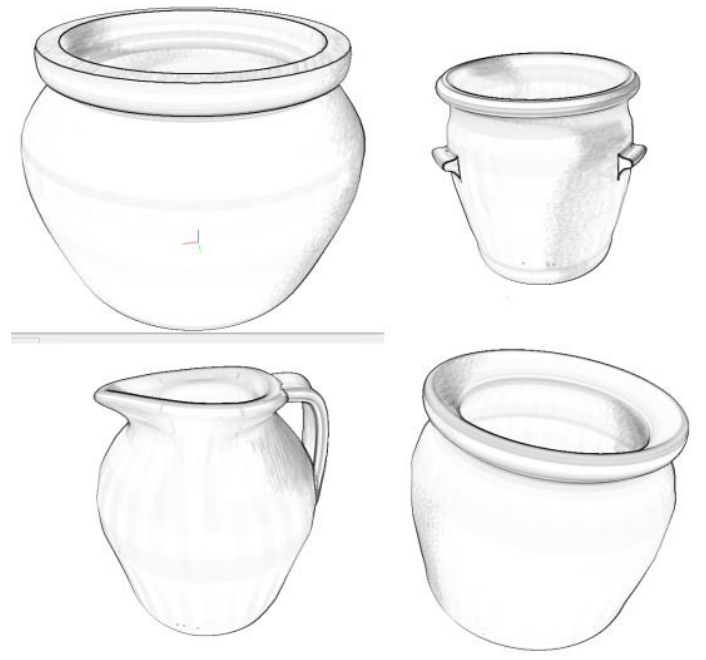

Figure 10. NPR theoretical model representation.

This should differ drastically from an amphora modelling where a theoretical model is designed a priori by the archaeological community and accept as a paradigm (and the difference is determined by the differences between the Roman productive system and the Medieval productive system; the first in in fact very similar to an industrial productive system). For example in the case of the Grand Ribaud F Etruscan wreck the regularity of the amphorae production allows us to use a modelling approach and to formalize this knowledge into a hierarchy of objects sharing the same properties and structured according to the Object paradigm in an ontology. In San Domenico case almost each object is the referent for a theoretical model and we had to process each object as an instance of a type defined only by itself. This is surely a limit of the method and we are working on a most simple way to formalise it.

\section{SOME RESULTS}

From an archaeological point of view the information gathered during the excavation of San Domenico have made possible to note some specific characters of the medieval masons' modus construendi:

- $\quad$ every vessel had his specific place: the bigger were placed at the center and the smaller were deposed around them;

- many pots, between other vessels and the choir's walls, were used as wedges;

- to balance the heights, between different vessels, small layer of mortar and bricks were deposed;

- $\quad$ every pieces of pottery had been accurately chosen and it had been put in a specific place;

- $\quad$ some big vessels, put vertically, were used to join different levels.

So the research, thanks also to the choices about technical documentation, has allowed archaeologist to study in detail the particular building technique, stressing the extreme skill of the medieval, specialized, masons. They used, in fact, a specific modus operandi which was based on the careful choice of materials and a precise way of deposing it, even if the vessels were not homogeneous in form and size.

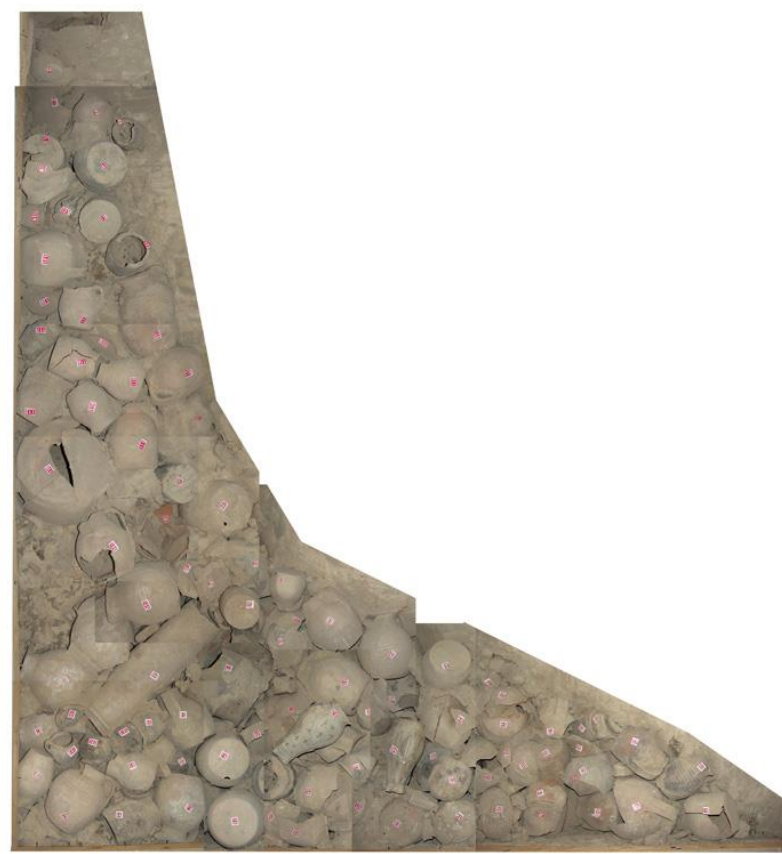

Figure 11. Layer (US) 2: orthophoto representation. 


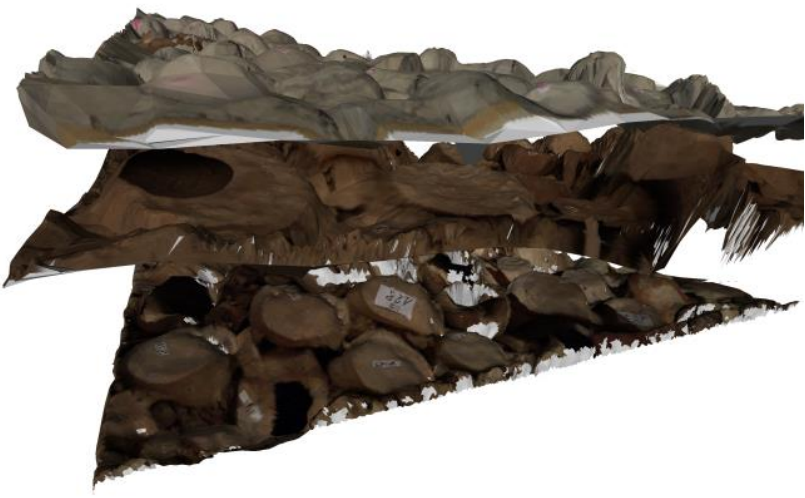

Figure 12. All three layers (US) are represented in the same reference system after the excavation.

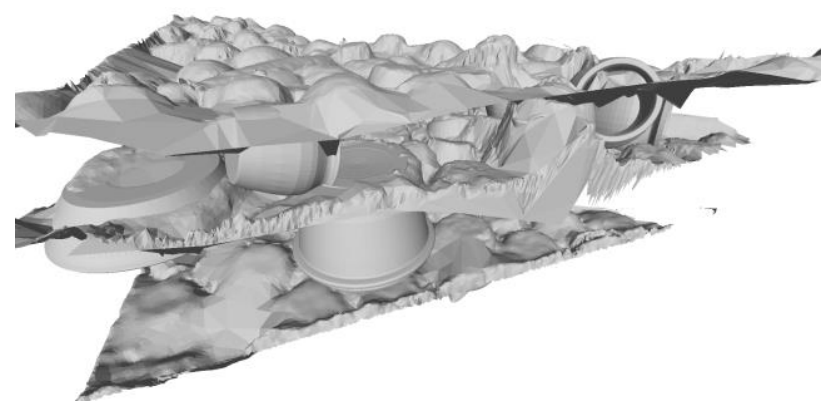

Figure 13. All the three layers (US) are represented in the same reference system with theoretical pottery inserted in the measured mesh.

\section{ACKNOWLEDGMENT}

We want to thank Daniela Peloso for her time dedicated to laser scanner post process, done on old data in quite unknown format and Amine Mahiddine doing his $\mathrm{PhD}$ on 3D object recognition that have used some data from this experimentation in his own work.

\section{REFERENCES}

Alcala, F., Alcocer, A., Pascoal, A., Alves, F., Bale, K., Chapman, P., et al., (2008., 10-12 July 2008). Virtual underwater exploration of Pianosa Island: a VENUS case study. Paper presented at the IKUWA3: The Third International Congress on Underwater Archaeology, London, UK.

Drap, P., Bruno, E., Long, L., Durand, A., \& Grussenmeyer, P., (2002, 2 au 6 Septembre). Underwater photogrammetry and XML based documentation system: The case of the 'Grand Ribaud F' Etruscan wreck. Paper presented at the SPRS, Commission V, Close Range visualization techniques, Corfu, Grèce.

Drap, P., \& Long, L., 2006, Fotogrammetria subacquea e Sistema Esperto, Il caso del relito etrusco Grand Ribaud F. in A. e. Roma (Ed.), Disegno e conoscenza, contributi per la storia e l'architettura (Vol. Collana di Studi e Ricerche sul Disegno dell'Architettura e dell'Ambiante, pp. 61-75). Roma, Italy: Eccigraphica S.r.l., Roma.
Drap, P., Seinturier, J., \& Long, L., 2003. A photogrammetric process driven by an Expert System: A new approach for underwater archaeological surveying applied to the 'Grand Ribaud F' Etruscan wreck. Paper presented at the Applications of Computer Vision in Archaeology ACVA'03 Monona Terrace Convention Center, Madison, Wisconsin, USA.

Harris, E.C., 1989. Principles of Archaeological Stratigraphy, London.

Pruno, E., Marcotulli, C., 2014. Orciolai e magistri de pietra: Prato (PO) nel XIV secolo, in Atti del XLVI Convegno Internazionale della Ceramica "Ceramica e architettura", Savona, 2014, pp. 101-116.

Vannini, G., 2001, Una struttura edile trecentesca: il complesso fittile del S. Domenico di Prato, in De Minicis E. (a cura di), I laterizi in età medievale. Dalla produzione al cantiere, Roma, pp. 199-212.

Vannini, G., Marcotulli, C., 2006. Prato. Chiesa di San Domenico: campagna 2006, in "Notiziario della Soprintendenza per i Beni Archeologici della Toscana" 2, Firenze, pp. 55-58.

Alcala, F., Alcocer, A., Pascoal, A., Alves, F., Bale, K., Chapman, P., et al. (2008, 10-12 July 2008). Virtual underwater exploration of Pianosa Island: a VENUS case study. Paper presented at the IKUWA3: The Third International Congress on Underwater Archaeology, London, UK.

Drap, P., Bruno, E., Long, L., Durand, A., \& Grussenmeyer, P. (2002, 2 au 6 Septembre). Underwater photogrammetry and XML based documentation system: The case of the 'Grand Ribaud F' Etruscan wreck. Paper presented at the SPRS, Commission V, Close Range visualization techniques, Corfu, Grèce.

Drap, P., \& Long, L. (2005a). Photogrammétrie et archéologie sous-marine profonde. Le cas de l'épave étrusque Grand Ribaud F. XYZ, 103 .

Drap, P., \& Long, L. (2005b). Photogrammétrie et archéologie sous-marine profonde. Le cas de l'épave étrusque Grand Ribaud F XYZ, $\mathrm{N}^{\circ} 103$, partie 1 et $\mathrm{N}^{\circ} 104$, partie 2, Vol 103: 119-126, Vol 104: 125-134.

Drap, P., \& Long, L. (2006). Fotogrammetria subacquea e Sistema Esperto, Il caso del relito etrusco Grand Ribaud F. In A. e. Roma (Ed.), Disegno e conoscenza, contributi per la storia e l'architettura (Vol. Collana di Studi e Ricerche sul Disegno dell'Architettura e dell'Ambiante, pp. 61-75). Roma, Italy: Eccigraphica S.r.l., Roma.

Drap, P., Seinturier, J., \& Long, L. (2003, June 17). A photogrammetric process driven by an Expert System: A new approach for underwater archaeological surveying applied to the 'Grand Ribaud F' Etruscan wreck. Paper presented at the Applications of Computer Vision in Archaeology ACVA'03 Monona Terrace Convention Center, Madison, Wisconsin, USA.

Skarlatos, D., Demestiha, S., \& Kiparissi, S. (2012). AN 'OPEN' METHOD FOR 3D MODELLING AND MAPPING IN UNDERWATER ARCHAEOLOGICAL SITES. International Journal of Heritage in the digital era, 1(1). 